\title{
Employment Outcomes of Graduates in Selected Higher Educational Institutions in Eastern Visayas, Philippines
}

\author{
Jane A. Austero, Pedro T. Armenia and Moises Neil V. Seriño
}

Department of Economics, Visayas State University, Baybay City, Leyte, 6521-A Philippines

\begin{abstract}
This study aimed to describe the socio-demographic profile of graduates and determine the major factors that affect employment outcomes of HEI graduates in Eastern Visayas, Philippines. It used secondary data from the graduate tracer studies in 2008, involving 2,097 sample graduates who were randomly selected by degree program and year graduated. Ordered logit regression was employed to determine the factors that significantly affect employment outcomes. Communication skills, human relation skills, information technology skills and problem solving skills were found to be the major skills and competencies of graduates with better employment outcomes. Moreover, graduates who earned honors and awards, had higher licensure examination rating, recommendation from influential personalities, good performance in walk-in application and appropriate response to job advertisements are more likely to be employed related to the degree taken up. Graduates in mass communication and documentation had the highest probability for the most favorable labor market outcomes, indicating that these graduates have better chances of being employed related to the degree they took up.
\end{abstract}

Key Words: ordered logit regression, labor market, graduate skills, job seeking, Philippine HEI

Correspondence: P. T. Armenia. Address: Department of Economics, Visayas State University, Baybay City, Leyte6521-A Philippines. E-mail: ptarmenia@gmail.com.

Tel: +630533352634

DOI: $10.32945 /$ atr3419.2012 


\section{INTRODUCTION}

The vision for higher education in the Philippines is to become the prime mover of the nation's socio-economic growth and sustainable development (UNESCO, 2009). Thus, as in all higher educational institutions (HEIs) throughout the country, HEIs in Eastern Visayas, Philippines aim to produce graduates ready and equipped with knowledge and skills to address the manpower needed in the job market. But despite these efforts, Montalvo (2006) showed that the cumulative employment growth in Eastern Visayas displays a considerable deep fall relative to the national average of employment growth. Orbeta (2002) pointed out that the utilization of college graduates among the employed has declined. This indicates that the quality of jobs held by college graduates has deteriorated. According to the UNESCO's National Education Support Strategy (UNESCO, 2009), there is a high percentage of unemployed who have reached the college level (22\%) and have graduated from college (19\%). This labor situation indicates that the educated unemployed possess skills which do not match the available job requirement - an issue of relevance to the curricula of higher educational institutions (UNESCO, 2009). These findings were echoed in a research conducted by Armenia (2008) on employment profiles of HEI graduates in Eastern Visayas that an alarming number of HEI graduates are not in the workforce. The National Economic Development Authority (NEDA, 2006), reported that the unemployment rate in the region went up to $4.7 \%$ from $4.5 \%$ in 2005 and the number of unemployed in the region reached 80,000 in 2006 from 76,000 in 2003. Underemployment also increased to 343,000 in 2006 from 282,000 in 2005.

The Commission on Higher Education (CHED) is the government agency responsible for formulating plans, policies and strategies relating to the development and efficient operation of HEIs in the Philippines (CHED, 2010). Rubio (2004) mentioned that the Philippines should make its workforce highly skilled and productive, thus, the need for higher learning. Billions of pesos are allocated to HEIs annually for further development and improved operation. Olea (2008) stated that the budget for 112 state universities and colleges (SUCs) throughout the Philippines is P22.57 billion ( $\$ 482.06$ million), based on the 2009 proposed National Budget. Despite this attention focused on education, there is still a high unemployment rate and 49.2\% (2009) of it falls in the age bracket of 15-24 years old. This age bracket is usually composed of fresh graduates from 
colleges and universities, implying that HEIs are producing graduates who cannot find jobs.

There are researches that investigate the determinants of labor market outcomes of graduates who are engaged in job search. Previous studies have typically found that age, gender, marital status and schooling are significant determinants of an individual's employment outcome (Edin, 1989; Bradley and Taylor, 1992; Narendranathan and Stewart, 1993; Lazaro et al., 2000). Lim et. al (2008) studied employment outcomes of graduates of Universiti Utara in Malaysia and found that the type of degree, ethnicity, and number of job applications are significant determinants of labor market outcomes and accounting graduates were found to obtain the best labor market outcomes. Dabalen et al., (2000) found that in Nigeria, employers complain that graduates are poorly prepared for work. They found that university graduates are poorly trained, graduate skills were deteriorating and that shortcomings were severe in oral and written communication and in applied technical skills. This resulted to high levels of unemployment (Dabalen et al., 2000). With regards to underemployment, Montalvo (2006) showed that age, level of education, gender, urbanity and region, plus time dummies were the relevant variables affecting underemployment in the Philippines using logit estimation. However, little information is available on the employment outcomes for Eastern Visayas in particular. This study was designed to fill that gap by providing useful insights of the employability of graduates from HEIs in Eastern Visayas. To the best of the authors' knowledge, this is the first attempt to analyze the employment outcomes of graduates in HEIs in the region.

There exists a certain relationship between HEIs' supply of graduates and the labor market demands for workers. The labor market sets the criteria and qualifications that their future workers should possess. The HEIs supply this demand of workers with graduates of particular skills, knowledge and competence in their respective areas of discipline. According to the labor secretary, Patricia Sto. Tomas, as cited by Remollino (2006), the job skill mismatch in the Philippines is a very serious matter that must be addressed and given sufficient priority in effectively dealing with employment and underemployment problems. Di Gropello (2010) reported that in view of the growing demand for skills in the Philippines, it is clear that there are initial indications of emerging skill gaps, suggesting that skills are becoming a constraining factor for the economy. The problem on the incompatibility between the academic programs offered by 
HEIs and the manpower needs of the industry is still presently a major concern in view of the heavily declining employment opportunities of new graduates, particularly in the Eastern Visayas Region. Accordingly, the quality of Eastern Visayas graduate education acquired from HEIs is an important factor to be studied because their employment outcome is heavily influenced by the region's manpower needs from different industries. Thus, this paper presents information about the sociodemographic profile of HEIs graduates and the factors which are associated with better employment outcomes. Results of the study will help HEIs focus on areas that will enhance the employability of their graduates.

\section{MATERIALS AND METHODS}

\section{Data Analysis}

Descriptive analysis was carried out to describe the socio-demographic profile of the respondents. In addition, regression analysis was employed to analyze the factors that affect employment outcomes of graduates in Eastern Visayas.

The model below was specified to analyze the factors affecting the employment outcomes of HEI graduates in Eastern Visayas. It hypothesizes that employability is a function of observed and unobserved characteristics of the graduate $\left(\mathrm{X}_{\mathrm{i}}\right.$ and $\left.\varepsilon_{\mathrm{i}}\right)$. That is,

$$
\mathrm{IE}=\mathrm{X}_{\mathrm{i}} \beta+\varepsilon_{\mathrm{i}}
$$

where IE is an index of employability (the greater the index the more likely that the graduate will achieve a better labor outcome), $\mathrm{X}_{\mathrm{i}}$ is a vector of observed characteristics with unknown weights and $\varepsilon$ is the error term. The employability status of graduates may depend on the qualities they possess that may match the needs of employers. The characteristics of graduates including age, marital status, type of degree program completed, communication and other skills, recommendations and academic performance and other important characteristics would affect their employment outcomes. In this study, employment outcomes are classified as: unemployed, self-employed, employed but not related to the degree taken-up and employed related to the degree taken-up. $\beta$ captures the 
relationship between the index of employability and the independent variables.

In order to understand which of the factors affect employment outcome, the regression model was postulated as follows:

EOUT

where:

EOUT

YG

DCIVSTAT

LEYTE

RATING

DHOA

DRECCMND

DCOM_SKILLS

DICT

DBUSADM

DEDUC

DPRSKILL

DWALKIN

DADVER

NTRAIN

e
= $\mathrm{f}($ YG,DCIVSAT,LEYTE,RATING,DHOA, DGDGRADES_HS , DRECCMND, DCOM_SKILLS, DICT, DBUSADM , DEDUC, DPRSKILL, DWALKIN , DADVER, NTRAIN ) $+\varepsilon$

= Employment Outcomes where, EOUT $=0$ if unemployed; EOUT $=1$ if self-employed; EOUT $=2$ if employed not related to degree taken-up; and EOUT $=3$ if employed related to degree taken-up

$=$ Year graduated expressed as year 1,2...(1=AY 2001-2002, $2=$ AY 2002-2003,..)

$=$ dummy variable for marital status of the graduate taking 1 if single and 0 if otherwise

= dummy variable of graduate from Province of Leyte taking the value of 1 and 0 if otherwise

$=$ Professional Regulation Commission (PRC) Rating expressed in percentage

$=$ dummy variable which takes the value of 1 for graduates with honors award and 0 otherwise

= dummy variable for graduate employed through the strength of recommendation taking the value 1 and 0 otherwise

= dummy variable for communication skills taking the value of 1 and 0 otherwise

= dummy variable for information technology skills taking the value of 1 and 0 otherwise

= dummy variable for business administration and related graduate the value of 1 and 0 otherwise

= dummy variable for education and related graduate taking the value of 1 and 0 otherwise

= dummy variable for problem solving skills taking the value of 1 and 0 otherwise

= dummy variable for graduates employed through walkin application taking the value of 1 and 0 otherwise

= dummy variable for graduates employed through response to an advertisement application taking the value of 1 and 0 otherwise

$=$ number of trainings attended by the graduate

$=$ random error 
In this case, the dependent variable was treated as ordinal scale and measured in the form: $y=0$ if unemployed; $y=1$ if self employed; $y=2$ if employed but not related to the degree program taken up; and $y=3$ if employed related to the degree program taken up. The specific ordering of the dependent variable is in accordance with labor market outcomes. The ordered logit model was appropriate for the analysis because the dependent variable is ordered and discrete.

Logistic regression can be used to predict a dependent variable on the basis of continuous and categorical independent variables and to determine the percentage of variance in the dependent variable explained by the independent variables. The impact of predictor variables is usually explained in terms of odds ratios. Logistic regression applies maximum likelihood estimation after transforming the dependent variable into a logit variable (the natural log of the odds of the dependent variable). In this way, logistic regression estimates the odds of a certain event occurring. Note that logistic regression calculates changes in the log odds of the dependent variable, not changes in the dependent variable itself as the ordinary least square (OLS) regression does (Hosmer and Lemeshow, 2000).

Logistic regression has many analogies to OLS regression: logit coefficients correspond to $b$ coefficients in the logistic regression equation, the standardized logit coefficients correspond to beta weights, and a pseudo $\mathrm{R}^{2}$ statistic is available to summarize the strength of the relationship. Unlike OLS regression, however, logistic regression does not assume linearity of relationship between the independent variables and the dependent, does not require normally distributed variables, does not assume homoscedasticity, and in general has less stringent requirements. It does, however, require that observations be independent and that the independent variables be linearly related to the logit of the dependent variable.

To evaluate the acceptability of the model, Log-likelihood Ratio Test was employed. The estimated model was subjected to multicollinearity diagnostic tests to check for any serious linear relationships that exist among predictor variables included in the model. The term multicollinearity implies that two or more variables (or linear combinations of variables) are near perfect linear combinations of one another. The primary concern is that as the degree of multicollinearity increases, the regression model estimates of the coefficients become unstable and the standard errors for the coefficients can be wildly inflated. 


\section{Data source}

The data used in the study were taken from the Graduate Tracer Studies (GTS) conducted under the project entitled "Employment Profile of HEI Graduates and Manpower Needs of Industries in Eastern Visayas Region". The database consists of data from about 2,097 sample graduates who were randomly selected by degree program and year graduated from six participating HEIs in Philippines Region 8. The six participating institutions were Visayas State University (VSU), Eastern Samar State University (ESSU), Palompon Institute of Technology (PIT), Northwest Samar State University (NwSSU), Saint Joseph College (SJC), and St. Paul Business School (SPBS). These schools are located in Region 8.

\section{RESULTS AND DISCUSSION}

\section{Profile and Employment Outcomes of Graduates in HEIs}

From the 2,097 sample graduates from six participating HEIs included in the study, $36.08 \%$ were unemployed, $5.89 \%$ were self-employed, $12.97 \%$ were employed in jobs not related to the degree taken up in college and $47.62 \%$ were employed related to their degree (Table1). The majority $(96.3 \%)$ of the sample graduates were from Region 8 . The highest percentage of the graduates were from Leyte $(41.8 \%)$ followed by graduates from Western Samar (20.7\%), Eastern Samar (17.5\%), Southern Leyte $(12.3 \%)$ and Northern Samar (3.6\%) provinces. With respect to employment outcomes and province of origin, a higher percentage of graduates from Leyte (52.9\%) and Southern Leyte (47.1\%) were employed related to degree. This could be attributed to the higher employment opportunities existing in Leyte and Southern Leyte compared to other provinces in the region.

Table 1. Distribution of HEI graduate by employment outcomes

\begin{tabular}{lcc}
\hline Status & Frequency & Percent \\
\hline Unemployed & 735 & 35.1 \\
Self-Employed & 120 & 5.7 \\
Employed but Not Related to Degree & 272 & 12.9 \\
Employed Related to Degree & 970 & 46.3 \\
$\quad$ Total & 2,097 & 100.0 \\
\hline
\end{tabular}


Following the Commission on Higher Education (CHED) degree clustering, a higher average rate of graduates employed relevant to their qualifications was observed from the graduates of Mass Communication and Documentation (70\%), Mathematics and Computer Science (57.1\%) and Home Economics (50.4\%). A higher average rate of graduates employed in jobs not related to skills was observed from the graduates of social and behavioral sciences $(23.7 \%)$, natural sciences $(22.2 \%)$ and general degree $(20 \%)$ clusters. Information technology (44.6\%), teaching $(28 \%)$, and problem solving $(11.9 \%)$ skills were the three major professional skills reported by sample graduates employed relevant to degree.

The major reasons of the sample graduates for taking their respective courses were affordability for the family (51.7\%), prospect for immediate employment (45.6\%), availability of course offering in chosen institution (39.6\%), influence of parents or relatives (36.6\%) and strong passion for the profession (35.0\%). Across all employment status, these reasons were consistent among unemployed, self-employed, employed but not related to degree and employed related to degree graduates.

A higher proportion $(79.5 \%)$ of sample graduates with honors and awards who were employed related to their degree, employed but not related to their degree and self-employed compared to those who were unemployed (20.5\%). Almost $20 \%$ of the sample graduates attended post graduate training sessions. The major trainings attended include other work related training $(31.7 \%)$, advance studies or graduate program $(28.1 \%)$ and short term professional related training $(27.4 \%)$. However, these trainings did not differ relatively across employment outcomes.

Graduates who were employed in jobs related to their degree found employment in education (30.7\%), wholesale and retail trade (12.8\%) and transport, storage and communication (12.3\%) companies. On the other hand, graduates who were employed but not related to the degree found employment in wholesale and retail trade (16.4\%), education $(14.8 \%)$ and public administration and defense, compulsory social security $(13.7 \%)$. Another way to know whether the graduates landed in jobs that they were prepared for in college may be viewed according to the type of company they found their jobs. The highest match of degree and classification of company could be observed with the education and training graduates where $60.6 \%$ were employed in an educational institution and fields. Other than this, majority of the graduates were scattered across around different classifications whichare mostly not related to their degree. On the 
other hand, only $32.9 \%$ of agriculture graduates were employed in agriculture and related fields while the rest were employed in other field of work. Graduates of business administration were employed in wholesale and retail $(12.7 \%)$, manufacturing $(8.9 \%)$ and other establishments. For trade, craft and industrial graduates, $35.1 \%$ were employed in transport, storage and communication while all others were spread out in other institutions. There is a high mismatch between degree and employment across all degree clusters of sample graduates. This finding is consistent with what the labor secretary, Patricia Sto. Tomas, claimed as mentioned by Remollino (2006) in his report.

With respect to how graduates found their job, there was no difference between the graduates who were employed related to degree and employed but not related to their degree. Graduates reported that they found the job through recommendation (38.4\%), walk-in application (35.8\%), information from friends (22.4\%) and advertisement (18.0\%). Majority of the graduates who were employed related and not related to degree waited for 1 to 6 months (34.3\%), 1 year to less than 2 years $(21.5 \%)$ and less than a month $(19.0 \%)$ before they were employed. Of those who responded to the question whether their first job after graduation was related to the degree, $65.3 \%$ claimed that their first employment was related to their degree while $34.7 \%$ said otherwise. However, close to half of the sample graduates $(42.6 \%)$ did not respond to the question. The $34.7 \%$ who have jobs not related to their degree mentioned that the major reasons for accepting a job even if it was not related to his/her degree were salary and benefits $(76.1 \%)$, career challenge $(49.4 \%)$, proximity to residence $(20.7 \%)$ and relationship to special skills (19.9\%).

The skills which were reported by graduates who were employed related to the degree as very useful in their jobs were human relations (82.4\%), communication (73.2\%) and problem solving skills (55.8\%). Graduates who were employed but not related to their degree reported the same, except that critical thinking skill (33.3\%) was more important than problem solving skills (26.7\%). With respect to initial gross monthly earning, graduates who were employed but not related to their degree earned less than the graduates who were employed related to their degree Perhaps this could be attributed to underemployment. Majority of the graduates who were employed but not related to their degree earned less than $\mathrm{P} 5,000$ pesos monthly while graduates who were employed related to degree earned P5,000 to about P10,000 monthly. Graduates who earn 
higher were graduates of engineering and technology, trade, craft and industrial and business administration and related fields.

One of the major reasons why graduates were not employed during the period covered by the study is that there were no job opportunities (55.3\%) for them. This is consistent with what Rubio (2004) and Remollino (2006) claimed that there is an insufficiency of jobs in the country, and that graduates have nowhere to go. Other major reasons include the grduates not looking for a job (35.9\%), lack of work experience (22.8\%), advanced $r$ studies $(9.5 \%)$ and health related reasons $(7.3 \%)$. Table 2 presents the reasons mentioned by the sample graduates who were unemployed at the time of the survey.

Table 2. Reasons why HEI graduates are not employed

\begin{tabular}{lcc}
\hline Reasons & Frequency & Percent \\
\hline No job opportunity & 384 & 55.3 \\
Did not look for a job & 249 & 35.9 \\
Lack of work experience & 158 & 22.8 \\
Advance or further study & 66 & 9.5 \\
Health-related reasons & 51 & 7.3 \\
Still looking for a job & 28 & 4 \\
Lack credential & 24 & 3.5 \\
Took up another course & 10 & 1.4 \\
Waiting for the application result & 9 & 1.3 \\
Resigned from a job & 8 & 1.2 \\
Review for board exam & 7 & 1 \\
Financial problem & 6 & 0.9 \\
No backer & 5 & 0.7 \\
Difficulty in finding job fitted to course taken & 3 & 0.4 \\
Birth certificate problem & 3 & 0.4 \\
Low salary/wage & 2 & 0.3 \\
Many applicants for one vacant teaching position & 1 & 0.1 \\
Focus on religious work and church-related & 1 & 0.1 \\
matters & & \\
\hline
\end{tabular}

a. Multiple responses percentages may add up to more than a hundred.

\section{Ordinal Logit Model}

To identify the major factors which statistically affect employment outcomes of HEI graduates, the ordered logit model was adopted. Table 3 shows the results of the estimated ordered logit model. The variables which were significant and with positive coefficients were honors and awards, PRC rating, communication skills, information technology skills, 
recommendation, originating from the province of Leyte, problem solving skills, walk-in job application and advertisement job application. Graduates with these qualities have better chances of being employed related to their degree, compared to those who do not have them. The significant result for honors and awards and PRC rating may be attributed to the perception of employers that graduates who perform well during college days will also perform well in the job as reflected by their academic ratings. The significant result for ommunication skills, which also conforms to the previous studies conducted by Cargile (2000) and Lan (2003), can be credited to the fact that employers prefer to employ graduates who can express their ideas well. The positive and significant coefficient on information technology skills can be attributed to the fact that nowadays, almost all transactions are processesed using higher technology applications and that a graduate's knowledge in information technology is an important requisite for employment. The importance of walk-in job application may be credited to the fact that good performance during impromptu job interviews is a good way to impress an employer. With respect to advertisement response job application, this maybe important because at present, most companies opt to post their job advertisements in websites and newspapers and sometimes specify that online applications will be prioritized, which could be an indication for the employer that the applicant is well-exposed in search engines, internet and use of basic computer applications.

Table 3. Ordered logit model estimates on factors affecting employment outcomes of HEIs graduates

\begin{tabular}{llc}
\hline \multicolumn{1}{c}{ Variable } & Coefficient & Std Error \\
\hline Single status & 0.194 & 0.118 \\
Year graduated & -0.071 & 0.049 \\
Honors and awards & $0.447^{*}$ & 0.259 \\
PRC rating & $0.004^{* * *}$ & 0.002 \\
Communication skills & $1.873^{* * *}$ & 0.135 \\
Information technology skills & $0.926^{* * *}$ & 0.17 \\
With recommendation & $1.062^{* * *}$ & 0.123 \\
Originated from province of Leyte & $0.242^{* *}$ & 0.111 \\
Business administration and related degree & 0.164 & 0.136 \\
Education and related degree cluster & $-0.347^{* * *}$ & 0.131 \\
Problem solving skills & $0.949^{* * *}$ & 0.157 \\
Walk-in job application & $1.085^{* * *}$ & 0.133 \\
Advertisement job application & $0.579^{* * *}$ & 0.178 \\
Number of trainings attended & 0.178 & 0.127 \\
\hline \hline
\end{tabular}

"significant at $1 \%$, "significant at $5 \%$, significant at $10 \%$ 
The education and related degree clusteris also statistically significant, but with negative coefficient. This implies that graduates of this degree cluster fall into lower employment outcomes. This may be attributed to the high rate of increase in the number of graduates from teacher education and education-related fields compared to the rate of increase in job availability for graduates in this field. Variables which yielded insignificant effect on employment outcomes include civil status, year graduated, business administration and related degree cluster and number of trainings attended.

Results of the ordered logit model show that HEI graduates who would likely have better employment outcome are those with honors and awards, high PRC rating, good communication and information technology skills, recommendation from influential personalities, originating from the province of Leyte, good problem solving skills, good performance during walk-in application, as well as appropriate response on job advertisement.

\section{Probability ofObtaining Labor Market Outcomes}

From the result of the regression analysis, average probability of employment outcomes was calculated by degree cluster. The average probability of obtaining various employment outcomes was calculated, holding all other variables at their sample means. Graduates of mass communication and documentation fields have the highest probability of obtaining better employment outcomes compared to all other graduates across all degree clusters. Graduates in trade, craft and industry, mathematics and computer science, engineering and technology and home economics also have higher probability of being employed related to their degree. On the other hand, general education and teacher training, law and jurisprudence, natural sciences, and social and behavioral sciences almost lower probability of being employed related to the degree. Observably, the graduates belonging to these degree clusters also have higher probability of being unemployed (Figure 1)

To detect multicollinearity, this study used the variance inflation factor (VIF) after regression. The result showed that the VIF and tolerance $(1 /$ VIF) values were not worrisome because there were no possible redundancy problem among all variables included in the model. All variables registered VIF values lower than 10 and a tolerance higher than 0.1 . In general, a variable with a VIF value greater than 10 and tolerance value lower than 0.1 may merit to further investigation. In addition, simple 


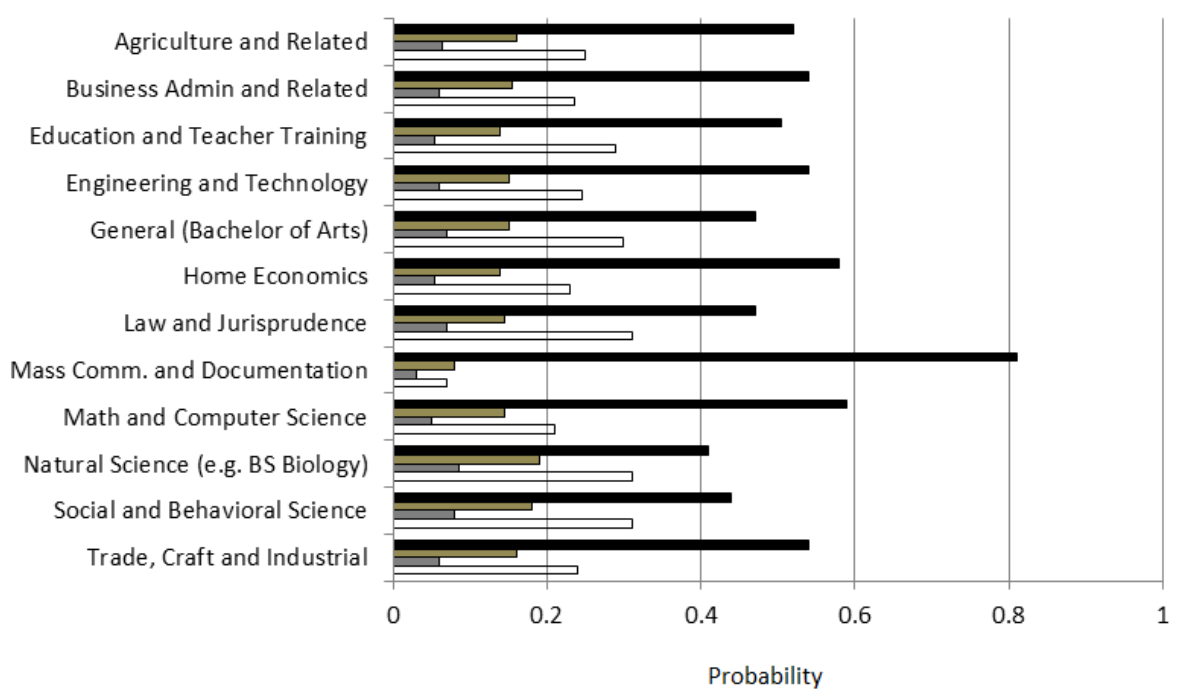

$\begin{array}{ll}\text { Employed related to the degree } & \square \text { Employed not related to the degree } \\ \square \text { Self-employed } & \square \text { Unemployed }\end{array}$

Figure. 1. Predicted Response Probabilities by Degree Cluster

correlation analysis was also conducted among independent variables to check if the variables are strongly correlated. Results showed that independent variables are weakly correlated. This may also serve as evidence to ascertain the claim that multicollinearity is not a serious issue for this study, although the authors recognize that multicollinearity problem is present but is tolerable.

\section{CONCLUSION AND POLICY IMPLICATION}

Based from the findings of the study, it is evident that communication skills, human relation skills, information technology skills and problem solving skills are the major skills and competencies necessary for HEIs graduates to have better employment outcomes. This implies that these skills should be more addressed by HEIs in Eastern Visayas in their curricular programs to improve the competency and employability of their graduates. Likewise, honors and awards, PRC rating and recommendations were associated with better employment outcomes of graduates. The positive and statistically significant coefficient of the province of Leyte dummy variable in the employment outcome of the ordered logit model 
indicates the comparably better employment opportunities available to graduates from Leyte province tcompared to graduates from other areas in the region.

This study also found that an alarming number of graduates were either unemployed or employed but not related to their college degree. This finding implies the absence or lack of employment opportunities for graduates who do not possess the necessary skills, trainings and knowledge needed by the employers. This suggests that HEIs or concerned government agencies should implement training programs to enhance employment opportunities aimed at improving the employment outcomes of graduates. The regular conduct of graduate tracer studies that include feedback on information from employers of graduates needs to be pursued to enable HEIs to update their information system on labor market demands and requirements. HEIs should be able to equip graduates with the necessary skills and knowledge needed by the labor market in order for the graduates to achieve better employment outcomes.

\section{REFERENCES}

ARMENIA, P.T. 2008. Employment Profile of HEI graduates and manpower needs of industries in Eastern Visayas Region, CHED-GIA Funded Research Project, Department of Economics, Visayas State University, Visca.

BRADLEY, S. and J. TAYLOR. 1992. An empirical analysis of the unemployment duration of school leavers. Applied Economics 24(1): 89-101.

CARGILE, A. 2000. Evaluations of employment suitability: Does accent always matters? Journal of Employment Counseling 37: 165-177.

COMISSION ON HIGHER EDUCATION (CHED). 2010. Information on higher education system. www.ched.gov.ph.

DABALEN, A., B. ONI and O. ADEKOLA. 2000. Labor market prospects for university graduates in Nigeria. Higher Education Policy, 14: 141-59.

DI GROPELLO, E. (2010). Skills for labor market in the Philippines. World Bank. 
http://elibrary.worldbank.org/content/book/9780821384893.

EDIN, P. A. 1989. Unemployment duration and competing risks: Evidence from Sweden. Scandinavian Journal of Economics 91: 653-53.

HOSMER, D. and S. LEMESHOW. 2000. Applied Logistic Regression. 2nd Ed. John Wiley \& Sons, Inc. Canada.

LAN, P.C. 2003. They have more money but I speak better English! Transnational Encounters between Filipina Domestics and Taiwanese Employers. Identities. Global Studies in Culture and Power 10: 133-61.

LAZARO, N., MOLTO M. AND SANCHEZ R. 2000. Unemployment determinants for women in Spain. Labor, 14: 53-78.

LIM, HOCK-EAM, J. RICH AND M.N. HARRIS 2008. Employment Outcomes of Graduates: The Case of Universiti Utara, Malaysia. Asian Economic Journal $22: 321-341$.

MONTALVO, J. 2006. Regional evolutions in labor markets in the Philippines: A dynamic approach. Journal of Asian Economics, 17: 448477.

NARENDRANATHAN, W. and M. STEWART. 1993. Modeling the probability of leaving unemployment: Competing risks models with flexible baseline hazards. Applied Statistics 43: 63-83.

NATIONAL ECONOMIC DEVELOPMENT AUTHORITY. 2006. www.nscb.gov.ph.

ORBETA, A. JR. 2002. Education, labor market, and development: a review of the trends and issues in the Philippines for the past 25 years. PIDS Discussion Paper No. 2002-19.

OLEA, R.V 2008. Debt Payments 48\% of Proposed 2009 Budget; Allotment for Services Measly Bulatlat, Volume VIII, No. 31, September 7-13, 2008.

REMOLLINO, A.M. (2006). Nowhere to go for most graduates: Jobs and 
graduates seriously mismatched. Bulatlat, Volume VI, No. 8, March 26 April 1, 2006.

RUBIO, M.G. 2004. Probing the Unemployment Problem, Policy Insights (PI-02-04) Senate Economic Planning Office.

UNESCO. 2009. UNSECO National Education Support Strategy Philippines. Manila, Philippines (UNESS). http://www.unesconatcom.ph/docs/education/uness_report.pdf 